\title{
COLD TESTS OF A SPOKE CAVITY PROTOTYPE FOR RIA
}

\author{
M.P. Kelly, K.W. Shepard, M. Kedzie, G. Zinkann \\ ANL, Argonne, IL, 60439, USA
}

\begin{abstract}
We report here results of high-power pulse conditioning of a superconducting niobium spoke cavity for the RIA (Rare Isotope Accelerator) project. The 350 $\mathrm{MHz}, \mathrm{v} / \mathrm{c}=0.4$ structure has a design accelerating gradient of $5 \mathrm{MV} / \mathrm{m}$. With the recent operation of a $5-\mathrm{kW}, 350$ $\mathrm{MHz}$ amplifier and a series of pulse and helium conditioning operations, the design goal has been met with an input power of less than $10 \mathrm{~W}$ at $\mathrm{T}=4.3 \mathrm{~K}$. Experimental measurements of the cavity mechanical and vibrational properties and measurements of X-rays resulting from field emission are presented. Results of additional cavity surface reprocessing using newly installed chemical polish and high-pressure rinse facilities will also be reported.
\end{abstract}

\section{INTRODUCTION}

A superconducting (SC) multi-ion driver linac for the RIA project will consist of more than $400 \mathrm{SC}$ cavities spanning nearly the entire velocity range $0.02<\beta<0.84$. Until recently relatively little development work in the intermediate velocity range $0.2<\beta<0.6$ had been performed [1]. Design and construction details of the ANL $\beta=0.29$ and $\beta=0.4$ single-cell spoke cavities were reported previously [2,3]. This paper reports detailed results of high power rf conditioning and surface reprocessing on the $\beta=0.4$ single-cell spoke cavity.

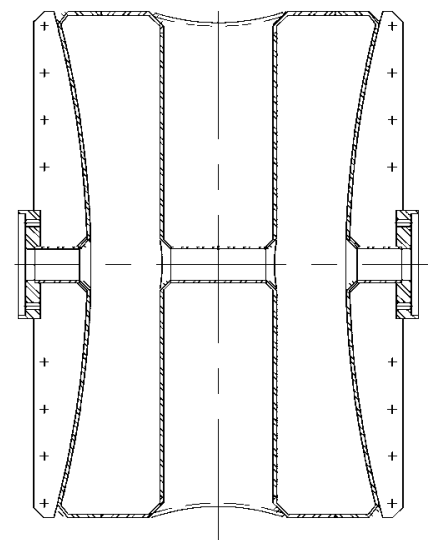

Figure 1: Section for a $350 \mathrm{MHz}$ prototype spoke cavity. The housing diameter is $44 \mathrm{~cm}$ and the active length (see text) is $29.8 \mathrm{~cm}$.

\section{CAVITY PERFORMANCE}

\subsection{RF and helium conditioning}

Initial processing of the critical cavity surfaces included a heavy $\sim 150$ micron electropolish just prior to the final closure weld followed by a very light chemical polish in a solution of 1:1:2 BCP (section 2.3). The cavity was then rinsed and filled with clean deionized water.

Tests following the initial cooldown to $4.5 \mathrm{~K}$ were performed with $110 \mathrm{~W}$ of $\mathrm{rf}$ power for pulse conditioning of mulipacting barriers. The observed low level $\mathrm{Q}$ was $\approx 6 \times 10^{8}$ corresponding to a surface resistance $R_{S}$ of 137 $\mathrm{n} \Omega$. BCS resistivity contributes $47 \mathrm{n} \Omega$ at this frequency and temperature. Following rf pulse and helium conditioning the highest accelerating field reached was $\mathrm{E}_{\mathrm{a}}=4.4 \mathrm{MV} / \mathrm{m}$ as shown in the bottom panel of Figure 2 .

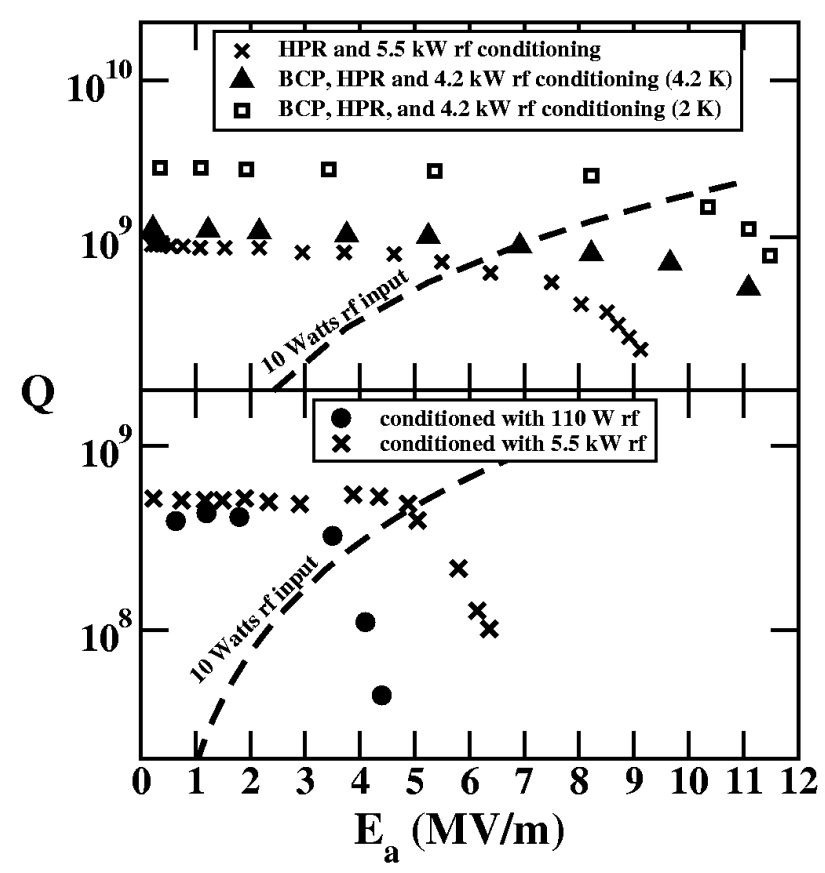

Figure 2: Results at $2-4.5 \mathrm{~K}$ following a high-pressure rinse and rf conditioning (top) compared to earlier results with only rf conditioning (bottom). Peak surface electric fields are equal to 4.0 times the average accelerating field for this geometry.

In this work $\mathrm{E}_{\mathrm{a}}$ is defined at the average accelerating field along the active length of the cavity for a particle moving with synchronous velocity $\mathrm{v} / \mathrm{c}=0.4$ and the active length is defined as the distance along beam axis as measured between the interior ends of the beam ports. $\mathrm{E}_{\mathrm{a}}$ was calibrated using the measured stored energy of $\mathrm{U}=85.3 \mathrm{~mJ}$ at $1 \mathrm{MV} / \mathrm{m}$ accelerating field taken from bead pull measurements. The calibration was checked by measuring bremsstrahlung $\mathrm{x}$-rays using a small 3 inch diameter $\mathrm{NaI}(\mathrm{Tl})$ detector placed outside the test cryostat. $\mathrm{X}$-rays resulting from field emission have a calculated maximum energy of $130 \mathrm{keV}$ at $\mathrm{E}_{\mathrm{a}}=1 \mathrm{MV} / \mathrm{m}$. $\mathrm{E}_{\mathrm{a}}$ was determined from $\mathrm{x}$-rays by scaling measured $\mathrm{x}$-ray end point energies for three accelerating fields in the range of 
3.5-6.0 MV/m. Results agree to within 3-8\% of the values of $\mathrm{E}_{\mathrm{a}}$ based on the stored energy.

The amount of rf power available at $350 \mathrm{MHz}$ was upgraded to $400 \mathrm{~W}$ and later to $5.5 \mathrm{~kW}$ enabling $\mathrm{cW}$ accelerating fields as high as $6.5 \mathrm{MV} / \mathrm{m}$ with no other surface reprocessing as shown in the bottom panel of Figure 2. Additional magnetic shielding was added to the test cryostat for these and all subsequent tests reducing the ambient magnetic field from approximately 15 mGauss to less than 3 mGauss. Multipacting was observed following every cooldown beginning at fields of less than $0.1 \mathrm{MV} / \mathrm{m}$ and continuing continuously up to $3 \mathrm{MV} / \mathrm{m}$. Conditioning times to reach $3 \mathrm{MV} / \mathrm{m}$ were one to two hours. Isolated multipacting levels at fields $\geq 4 \mathrm{MV} / \mathrm{m}$ were exhibited but required conditioning for only several minutes. Electron loading, first evident around $3 \mathrm{MV} / \mathrm{m}$, was reduced by conditioning with short duration $(\sim 10 \mathrm{~ms})$ high-power pulses and the cavity strongly overcoupled. The decrease in loading saturated after an additional few hours of conditioning. A coincident decrease in the low level $\mathrm{Q}$ by $10-15 \%$ after high power conditioning was observed following several cooldowns, however, the original $\mathrm{Q}$ could be regained by cycling the cavity to room temperature and bringing it up to atmospheric pressure through a 0.5 micron filter. Further high power conditioning generally reintroduced the $\mathrm{Q}$ drop. The mechanism for this effect is not yet understood.

\subsection{High-pressure rinse (HPR)}

A new high-pressure rinsing system consisting of a high-pressure pump, a spray wand and a custom spray nozzle has been used to remove particulates from the interior cavity surface. This treatment was performed twice shortly before completion of a new chemical polish facility and once after the BCP treatment.

The system was adjusted to supply 15 liters of water per second through eight $6.1 \mathrm{~mm}$ diameter jets at a nozzle pressure of 1700 PSI. The pressure is higher than those reported elsewhere, however, tests on niobium samples at pressures up to 2100 PSI revealed no damage under a high powered optical microscope. It should be noted that the relevant physical quantity is the jet velocity which is determined by the nozzle geometry and pressure. This velocity was measured to be $150 \mathrm{~m} / \mathrm{s}$ for a pressure of 1700 PSI. Rotational speeds for the spray wand were $\approx 2$ $\mathrm{rpm}$ with a horizontal speed of $1 \mathrm{~cm} / \mathrm{min}$. The cavity was rinsed for 60 minutes through the beam ports with the coupling ports aligned vertically for drainage.

Detailed chemical analyses of the water flowing into and out of the HPR system for 28 different anions showed no contaminants to the level of the test sensitivity (10-50 ppm). Similarly no dissolved solids were measureable to a level of 1 part in $3 \times 10^{6}$ by weight. The water resistivity measured $\sim 18 \mathrm{M} \Omega \mathrm{cm}$ after flushing the system for 30 minutes. Rinsing was followed by two days of drying as clean dry nitrogen was flowed in through a coupling port. The entire HPR and drying was process performed in a class 100 clean area. Transport to the test area and fitting with rf couplers was performed with the cavity under a nitrogen purge.
Results at $4.5 \mathrm{~K}$ are shown in the top panel of Figure 2. The $\mathrm{Q}$ at low power levels increased to $9 \times 10^{8}$ or by about $15 \%$ over the highest value observed prior to the highpressure rinse. The residual surface resistance is $38 \mathrm{n} \Omega$. Following high-power pulse conditioning significant field emission was observed only at relatively high accelerating fields. The highest accelerating field reached prior to the $\mathrm{BCP}$ was $9.2 \mathrm{MV} / \mathrm{m}\left(\mathrm{E}_{\mathrm{PEAK}}=37 \mathrm{MV} / \mathrm{m}\right)$.

\subsection{Buffered Chemical Polish (BCP)}

A new facility for chemical polishing was used to etch the interior surface of the cavity in an effort to further increase performance. The facility consists of gravity fill tanks for acid and water, a water cooling tank to moderate the cavity temperature during the etch, and a recirculation pump to agitate the acid solution.

The BCP was performed using a standard 1:1:2 solution of $48 \%$ hydrofluoric, $69 \%$ nitric and $85 \%$ phosphoric acids obtained premixed in 55 gallons containers. The cavity was etched on two separate occasions for 60 minutes and 45 minutes at an acid temperature maintained in the range $12^{\circ}-18^{\circ} \mathrm{C}$. Acid was recirculated through the beam ports during the second polish at a rate of 20 liters/minute to help remove the evolved gas. A total of $123 \mu \mathrm{m}$ of material was removed from the surface.

Cavity results at 4.2 and $2 \mathrm{~K}$ following BCP treatments, a high-pressure rinse and high power rf pulse and helium conditioning are shown in the top panel of Figure 2. The $\mathrm{Q}$ at $4.2 \mathrm{~K}$ for low input power is approximately $10 \%$ higher than the value obtained following the HPR treatment alone. However, field emission has been dramatically reduced even for the highest stable accelerating field of $11.5 \mathrm{MV} / \mathrm{m}\left(\mathrm{E}_{\mathrm{PEAK}}=46 \mathrm{MV} / \mathrm{m}\right)$. The design goal of $5 \mathrm{MV} / \mathrm{m}$ is achieved with $5 \mathrm{~W}$ of input $\mathrm{rf}$ power at $4.2 \mathrm{~K}$.

\subsection{Anomalous BCP etch rates}

The premixed acid in the 55 gallon drums was chemically analyzed before use along with a 1:1:2 BCP sample manually mixed from small bottles of fresh reagent. Concentrations of $\mathrm{F}, \mathrm{NO}_{3}^{-}$, and $\mathrm{PO}_{4}^{3-}$ anions in both mixtures were similar, however, it was observed that the manually mixed BCP exhibited a very high etch rate on small niobium samples if used immediately after mixing. One test performed with $150 \mathrm{ml}$ of freshly mixed BCP and a $1 \times 2 \times 1 / 8$ inch niobium sample exhibited a potentially dangerous temperature increase in the $\mathrm{BCP}$ solution of $22^{\circ} \mathrm{C}$ to $52^{\circ} \mathrm{C}$ in 1 minute. Approximately 24 hours later the same solution showed an etch rate of $\approx 1$ $\mu \mathrm{m} /$ minute at $15^{\circ} \mathrm{C}$, similar to that of the premixed solution. The etch rate was also measured to increase by approximately a factor of two per $10^{\circ} \mathrm{C}$ increase in temperature.

\section{MECHANICAL PROPERTIES}

Eigenfrequency variations of the spoke cavity may be roughly divided into slow and fast components. Slower variations are generally due to uniform pressure changes 
on the cavity exterior and may be compensated for using a suitable slow tuner. Faster variations are due to the excitation of microphonics and may be reduced by increasing the cavity stiffness and which raises the frequency of acoustic vibrations and typically reduces the vibration amplitude. A fast tuning device is generally using to compensate for frequency shifts due to microphonics.

To reduce the spoke cavity deformation under external pressure changes the 17 inch diameter bulkheads at either end of the cavity have been dished inwards by 1.2 inches. Stiffness was increased further by welding support gussets to the bulkhead exterior, as shown in Figure 1. Even so, the largest eigenfrequency shifts are due to deformation of the bulkheads under uniform changes in the external pressure.

The frequency response of the cold spoke cavity to an external pressure change was measured by pumping on the cryostat, initially at a pressure of 785 Torr and measuring the shift in the resonant frequency as the pressure was reduced to approximately 30 Torr. The observed shift of $126 \mathrm{kHz} /$ atmosphere was linear within the measured range and agrees fairly well with the value of $105 \mathrm{kHz} /$ atmosphere taken from finite element analysis calculations. These results have been used to in the design of new drift tube structures designed for RIA [4,5].

The spoke cavity geometry, based on a short, large diameter inner cylinder supported at both ends, is inherently stiff compared to typical quarter wave structures. However, cavity vibrations due to various sources still lead to frequency variations.

The acoustic properties of the spoke cavity have been examined cold and at room temperature using a digitally recorded phase error signal from a phase-locked-loop circuit. A series of impulses was applied to the cavity housing and the Fourier spectrum of the error signal was monitored as the cavity relaxed. Transient vibrations damped in approximately $100 \mathrm{~ms}$. Tests at frequencies up to $1 \mathrm{kHz}$ revealed a single readily excitable mode lying at just under $500 \mathrm{~Hz}$. During normal operation in the test cryostat with the system removed from the ATLAS refrigeration loop the peak-to-peak frequency shifts were about $20 \mathrm{~Hz}$ in amplitude. It should be noted that nearly all rf test results presented here were obtained with the test cryostat connected to the helium refrigeration loop of the ATLAS linac, so that test conditions are similar to those of a real linac environment.

\section{CONCLUSION}

A prototype $\beta=0.4350 \mathrm{MHz}$ spoke loaded cavity has been successfully tested at stable $\mathrm{cw}$ accelerating fields up to $11.5 \mathrm{MV} / \mathrm{m}\left(\mathrm{E}_{\mathrm{PEAK}}=46 \mathrm{MV} / \mathrm{m}\right)$. Surface reprocessing using new ANL chemical polish and high-pressure rinse facilities has resulted in a low level $Q$ value above $10^{9}$ at $4.2 \mathrm{~K}$ characteristic of a residual surface resistance of 28 $\mathrm{n} \Omega$. The design goal of $5 \mathrm{MV} / \mathrm{m}$ has been achieved with an input rf power of 5 Watts.

An optimized two-cell version of the single spoke cavity has been designed and will form one of a set of six drift tube structures [4] designed to span the velocity range needed for the RIA driver linac.

\section{ACKNOWLEDGEMENTS}

This work was supported by the U.S. Department of Energy, Nuclear Physics Division, under contract number W-31-109-ENG-38.

\section{REFERENCES}

[1] J.R. Delayen, et al., in Proc. 1993 Particle Accelerator Conf., May 17-20, 1993, Washington D.C., 1715 (1993).

[2] K.W. Shepard, et al.,

[3] K.W. Shepard, et al., in Proc. of the 1999 PAC, March 27-April 2, 1999, New York, NY.

[4] K.W. Shepard, T.E. Tretyakova, in Proc. 2000 Linear Accelerator Conference, August 21-25, 2000, Monterey, CA, (2000).

[5] K.W. Shepard, et al., these proceedings. 